\title{
Enhancing Qualitative Research to Postgraduates Through Training
}

\section{Thuledi Makua*}

Professor, University of South Africa, South Africa

*Corresponding Author: Thuledi Makua, Professor, University of South Africa, South Africa.
Received: November 24, 2021

Published: January 25, 2022

(C) All rights are reserved by Thuledi Makua.

\begin{abstract}
The purpose of this paper was to explore and develop the knowledge of the postgraduate researchers registered in masters and doctoral degree programmes at various universities. A Participatory Action Research as an empowering approach was used and twenty government employees were invited from Kwa Mhlanga area, in Mpumalanga Province, South Africa to voluntarily participate over a period of sixteen-weeks of contact sessions. Through interviews the participants verbalized their frustrations and needs for research skills. The lessons learnt from the project were communicated through participants self-reporting. Thematic analysis revealed that (1) participants do not have formal opportunities for research training from the basic training institutions and employer, and (2) not understanding what research is from basic education, participants do not have courage to register for research studies at tertiary institutions. The project enhanced the participants' knowledge and understanding of qualitative research methodology in the way that they reflected it through diverse choices.
\end{abstract}

Keywords: Emotional Intelligence; Enhancing; Postgraduate Researcher; Qualitative Research; Training

\section{Introduction}

Training researchers has taken a new form of urgency in South Africa as the government is now looking for scientifically based information in its services. Qualitative research is a home to many different scholars [1]. According to Sandelowski and Leeman "qualitative research is an essential component used by different disciplines in intervening and developing programmes" [2]. Some companies conduct qualitative studies to investigate the problems they have and improve their service delivery. Chenail corroborated that researchers and scholars around the world have produced a sizable body of literature focusing on learning and teaching qualitative research [3]. Different private institutions use the expertise of the qualitative research scholars in their advisory boards to describe the challenges they face. A scholarly qualitative research starts with the identification of a problem which is tightly focused and supported by literature. I used the accessed data for the identification of the problem and solution seeking.
Clark and Sousa stated that "applied qualitative research is used widely by different practitioners and clinicians to access data needed to make a decision". In some instances the policy makers employ the service of the qualitative researchers to develop and amend their acts in relation to the qualitative findings [4]. The postgraduate qualitative researchers need to be guided on the skills of how to access data which serve as the point of departure. Accessing the already collected qualitative data from various qualitative research resources is a skill that the postgraduate researcher should learn from the project. Sandelowski stated that in order to generate comprehensive qualitative research knowledge the postgraduate researcher uses the accessed data from different qualitative resources [1]. The postgraduate researchers need support and mentoring on how to access and use qualitative research resources [4].

Savenye and Robinson further said that "qualitative research is based upon paradigms that are unfamiliar to some postgraduate researchers and most of them received little training in qualitative 
research during their masters' studies". To the postgraduate researcher the word research draws mixed reactions as they were not familiar with research concepts that would enable them to interact effectively with research experts [5]. They find it difficult to generate a qualitative research idea that could enhance the development and improvement of services; an idea that could result from gaps in the literature, recommendations, and other studies' limitations.

Part of the qualitative skills that the postgraduate researcher needs to develop into is to be an emotionally intelligent qualitative researcher. The emotionally intelligent qualitative researcher is the researcher who demonstrates good self-reflection, active listener, empathetic to participants and provides a safe environment for the participants to share even the dangerous information. These are the skills that can help the postgraduate researchers to be competent in their research. Learning about emotional intelligence in qualitative research in Collins and Cooper words "reveals the intertwined emotions that both the researcher and the participant have". The qualitative researcher as the instrument, need to possess the emotions that will not evoke negative reactions from the participants during data collection [6]. Guiding the postgraduate researchers about the emotional intelligence will assist the postgraduate researchers to improve their fieldwork skills. The project intended to rigorously train the postgraduate researchers in using personal and social competency areas of emotional intelligence as they play basic roles in handling relationships during qualitative research.

Spiers, Paul, Jennings and Weaver reiterated that "Teaching undergraduate qualitative research can be challenging". Involving the postgraduate researchers themselves in planning their training is vital for the success of the project [7]. The participants' narratives during the interviews shaped the project and gave it the direction and plan of intervention. The postgraduate qualitative researchers needed basic technical skills offered through extended structured period. A period of one to two years with regular participation in research methods conferences enhances the postgraduate research skills. This is described mostly in Lave and Wenger's theory of situated learning [8]. The theory is influenced by two concepts: community of practice ( $\mathrm{CoP}$ ) and legitimate peripheral participation. In community of practice the participants engage themselves mutually in practices of qualitative research skill development. It was mentioned by Wenger, 1998 in Schulze that "As postgraduate researchers acquire the knowledge and skills of the practice, they move to more central participation and eventually assume the role of experts" [9]. In legitimate peripheral participation the postgraduate researcher is guided from the periphery to the centre of qualitative research by being encouraged to participate actively during the sessions. Active participation in the form of home activities, presentations and accessing information from qualitative research resources move the postgraduate researchers from postgraduate without knowledge to postgraduate with knowledge level. In support of community of practice, the Constructivist learning theory concurs by saying that "learning is the process of constructing knowledge" [9]. In line with these theories the qualitative postgraduate researchers were referred to relevant information sources such as research methods conferences to acquire the qualitative research knowledge and skills of the practice. They were introduced to qualitative research resources such as books, articles, journals and a wide variety of internet resources to broaden their knowledge on qualitative research resources. The postgraduate researchers were guided on websites such as www.iqm.ualberta. ca and www.ijqm.sagepub.com. Browsing through these websites empowers the knowledge of the postgraduate researchers as they get notifications about, amongst others, qualitative conferences, workshops, scholar programmes as well as the different articles authored by qualitative research scholars.

\section{Purpose}

The purpose of this paper was to describe and explore the knowledge of the postgraduate qualitative researchers who aspired to conduct the qualitative research for their professional and postgraduate qualification. The postgraduate qualitative researchers were provided with the skills and knowledge as starting points of becoming skilful and informed qualitative researchers. The postgraduate researchers were guided to the appropriate use of qualitative methods by introducing them to qualitative approaches, methods of data collection, interviewing and observation, data analysis and reporting qualitative findings.

\section{Methodology}

The research design used was Participatory Action Research. The design constituted the sample of twenty participants with minimum qualification of masters who volunteered from the government institutions to take part in the project. The sampling was not to achieve representativeness but to inductively explore the academic development through qualitative research and func- 
tionality of the participants at the workplace. The government employees with the criterion of under masters' qualification and who intend to make a difference in their academic lives were purposefully selected. The ethical considerations were considered by getting the project approval from the University of South Africa and permission for the participants to partake was requested from the government institutions. The verbal consent was obtained from the participants. As participatory research project, in the form of lectures, anonymity amongst the participants was not easy to maintain as sharing of ideas during active participation in one class was encouraged even by the participants themselves.

Even though I made major reference to Spiers., et al. Qualitative Teaching Strategies, I used the DeLuca, Gallivan, and Kock five key steps of action research [10]:

- $\quad$ Step 1: Diagnosing the problem [10]. Pre-interview sessions were held and the participants narrated their need for development with regard to qualitative research methodologies. Formal individual interviews were conducted with participants at different areas of their choice. Keeping anonymity as to who said what during the interviews was not easy as the participants themselves discussed amongst themselves as part of recruiting each other. New information related to the interviews kept coming up during the lectures. The participants felt that this is the way of supporting and encouraging each other that they need development. They felt that unless they discuss and show each other their problems they may not come together into a project. Discussing openly was for their benefit.

- Step 2: Planning the action [10]. To meet their needs narrated during interviews, lectures with active participation were identified as the convenient mode of intervention. The project was divided into sixteen alternative weeks throughout the first year and nineteen weeks the second year. The participants chose the alternative weeks of contact sessions. Based on the dates chosen the programme was drawn and discussed with the participants.

- $\quad$ Step 3: Taking the action [10]. The lessons were facilitated in the form of lectures. Active participation was encouraged with the participants giving and discussing the experiences of their work places. It was easy to explain to the postgraduate researchers the five qualitative approaches (narrative, ethnography, phenomenology, case studies and grounded theory) using their experiences. At the end of each session home activities were given to the participants to work at home and present at the following session. The participants were guided on developing a qualitative research enquiry from proposal drafting to reporting and preparing a paper for conference presentation. During the sessions the participants practiced how to develop a paper for presentation and at the end two papers for conference presentations were developed and presented in the International Caritas Consortium, 2015, South Africa. They were not only guided on how to develop a presentation paper but also on how to prepare for publications. Clark and Thompson warned that "we have rejections and frustrations journals less familiar with qualitative research" [11]. The Five Tips for Writing Qualitative Research were used to guide the postgraduate researchers on choosing the journal and submitting manuscripts [11].

- $\quad$ Step 4: Evaluating the results [10]. At the end of sixteen weeks the participants were requested to evaluate and discuss the project from day one to the end. The participants used paper and pen to self-report their lessons learnt from the project. They participants were asked to discuss what they learnt from the project. Papers were submitted to the researcher as a collected data for analysis and reporting.

- $\quad$ Step 5: Specifying lessons learned [10]. The participants' learned lessons were subjected to a normal qualitative data analysis. In qualitative research, data analysis occurs concurrently with data collection and in this study data analysis occurred concurrently with data collection and evaluation of lessons learnt was specified in the form of data analysis for the purpose of final reporting.

\section{Data analysis}

I used thematic analysis to analyse the data collected from the participants' right from the first day. I used this method to analyse both the audiotapes and the written responses the participants gave. The audiotapes contained the interviews from the beginning of data collection and the data analysis occurred concurrently with data collection. In the written responses the participants were narrating the lessons they learnt from the project. Thematic analysis was performed using an adapted Colaizzi, seven steps of analysis [12].

\section{Step 1}

Acquiring a Sense of Each Transcript [12]. The audio tapes from all the interviews were repetitively listened to with the purpose 
of revealing the needs expressed. Sometimes the audiotapes were listened to four or five times. The written responses too were read to repetitively with the purpose of understanding the meanings in the words and sentences written. One participant commented during the interview that "I do not know where to start when I am expected to conduct a mini research". The participant here was echoing the frustrations they have as postgraduate researchers. In the evaluation of lessons learnt comments of satisfaction were narrated as participant one wrote: "I gained much about qualitative research like interviewing deeply to get the information from the participant".

It was not only gaining information, as the same participant continued below to say that she feels she can attempt to conduct research studies. "One developed much from the university context as of now I can do research studies of different problems that on comes across in life".

This was concurred by Schulze that as the participants gain confidence in what they have learnt they start to take the central position and become experts [9]. It was practice and active participation as seen this project that made participants feel that "now I can do research study".

Step 2

Extracting Significant Statements ${ }^{12}$. The transcripts were read several times with the purpose of identifying and extracting significant statements. There was no understanding of what qualitative research is as participant fourteen said "I heard that there is qualitative and quantitative but I do not know which is which". Hearing such comments from the interviews the researcher facilitated the presentations in most simplified manner as the participant commented as follows in the lessons learnt: "I have attended only one lecture but from the session I have gained a lot of information that made it easier for me to understand what qualitative research is. Initially I did not".

The information was presented in the simplified manner to enable the postgraduate researchers to follow and differentiate the qualitative concepts from quantitative studies.

Step 3

Formulating meanings [12]. As I was formulating the meanings out of the significant statements, the researcher was, according to Streubert and Carpenter observing own personal emotions that may influence the significant statements related to the experiences [13]. Each significant statement was studied very carefully to determine a sense of its meaning. Participant sixteen echoed her fear of research by saying: "I heard that research is difficult you cannot just understand it easily". I used the participants' examples to simplify the descriptions of qualitative concepts and approaches. From the lessons learnt the participants proposed that the project should continue the following year as they felt that they needed more information for them to understand what qualitative research is. Participant five wrote: "I would like us to continue with the classes next year".

Participant five was motivated by participant eleven who wrote that "Unisa contacts helped me a lot. I was motivated by Dr Makua on qualitative research and I even managed to present my research at International Caritas Conference".

Participant eleven continued to indicate that even though she had Masters Degree, the information received from the project was more beneficial. She echoed her satisfaction by saying: "when we started the research contact sessions with the Unisa team I did not think I can be able to conduct qualitative study anymore because I really struggled to complete my first research where I completed my MCur in nursing management".

Step 4

Theme clusters [14]. After I had formulated meanings from the significant statements, the formulated meanings were used to develop the themes (Table 1). Two themes emerged.

\begin{tabular}{|l|}
\hline Themes \\
\hline No formal basic research training \\
\hline Courage to register for research studies \\
\hline
\end{tabular}

Table 1: Themes.

Step 5

Exhaustive description [12]. In this study the researcher presented the themes into an exhaustive description of the participants' needs.

Step 6

Statement of identification [12]. The participants' personal perceptions of research were a unique combination of not having proper basic training in research and fear of failing if they attempt postgraduate studies.

Citation: Thuledi Makua. "Enhancing Qualitative Research to Postgraduates Through Training". Acta Scientific Medical Sciences 6.2 (2022): $153-158$. 
Step 7

Participant verification [12]. In accordance with Colaizzi, statement, in this study, trustworthiness was ensured by verifying the findings of the project with the participants. The participants were satisfied with the project findings and interventions.

\section{Results and Discussions}

\section{Theme 1: No formal basic research training}

The participants narrated that "research during my under graduation studies was just a chapter; I did not write an examination on research methodology". With such comments from the participants, the sessions were structured in such a way that they get an opportunity to discuss and write home activities as a form of practice. In accordance with constructivist learning theory, active involvement of the participants in the qualitative sessions' activities made them feel they have improved in their research skills. They narrated that they experienced their lack of research skills when the employer expected them to conduct a scholarly inquiry for service improvement.

It was during the interview that one participant indicated that she completed her Masters degree but she was not so sure of the methodology used. The participant said: "I do not remember well but I think I used quantitative.....mmmh what is the difference... quantitative and qualitative?" The participant feels that her supervisor hurried her to finish her studies by saying: "it is just that my supervisor did not give me time to understand as she complained that I am taking too long to complete my study".

Theme 2: Courage to register for research studies

Having no knowledge of what research is all about many participants do not have courage to risk registering post-graduation studies. They have fear of failing after committing a lot of money. The project simplified the research methodology as participant eight said: "now I can differentiate between the research designs". As stated by Wenger that as the participants gain research skills they contact other university lecturers and that afforded them the opportunity to cross boundaries to other research methodologies.

The participants felt that they have gained knowledge and insight in qualitative research processes as participant nineteen said: "I wish I had this knowledge during my under graduate studies". The participant continued writing about the lessons learnt by saying: "the presence of Unisa facilitators has really made a great im- pact on the knowledge I had. They put the information in a simple and understandable way giving also relevant examples that were more informative".

Not only simplifying research to them as participant eight wrote, but also demonstrating to them the differences between qualitative research and quantitative data collection. Different data collection methods that distinguish qualitative from quantitative research such as interviewing, observation, note taking were demonstrated to the participants. Participant thirteen commented how she benefitted, specifically about data collection and sampling by saying: "I have learned that it is possible to be directed by another person to get information from the other person (snowball) when collecting data".

Seasoned qualitative researchers are mindful of their emotions throughout the research process [6]. Participants wrote that they learnt that it is the relationship and emotions that the researcher creates that influence the data collection: "it assisted us to know that as a researcher I should create rapport with participants so as to gain information and also believes, culture and behaviour should not sort of influence the decisions from participants".

This was concurred by Collins and Cooper by saying: "Qualitative scholars assume that important quality of a researcher is characterised by self-awareness and better social interactions" [6]. It is of course Luttrell who further stated that emotional reflexivity and social interactions are important skills in qualitative research [14]. The qualitative researcher creates therapeutic and trustworthy environment for the participant to feel free and safe to narrate the experiences [15].

\section{Conclusion}

The aim of the project was to train the postgraduate researchers in qualitative research skills. Collins and Cooper stated that "many postgraduate researchers either deny their feelings or struggle to identify those feelings about their research needs" [6]. From the findings it can be concluded that the project was generally successful in reaching its objectives.

In this project learning was an active process as described by the Constructivist learning theory. The participants volunteered to partake in the project for the purpose of their academic development and performance appraisal by their employer. Active par- 
ticipation in the home activities ensured their adequate knowledge accumulation. Presentations of home activities during the sessions activated discussions amongst the participants and clarification from the researcher. Bringing in their experiences into their presentations as examples assisted me to use them in relation to the five qualitative approaches. This simplified the research that the participants regarded as difficult due to lack of basic training as one remarked as follows about the qualitative research interviews: "I gained much about qualitative especially when we were guided on how to interview the participant deeply to get more information".

Most participants reported to have gained research knowledge and skills. Some participants gained courage to write qualitative presentation papers for the conference. Lack of research skills discourages individuals to register for post-graduation studies. At the end of the project some participants verbalised intention to register for masters and postgraduate studies. Those who qualified to enter the post-graduation studies had already applied for admission. The interest shown by the participants has encouraged the facilitator to expand it to the other needy areas such as KwaMhlanga area. In this area participants started by wishing to be guided on tertiary institution application process. They wanted to work and correct their qualitative research proposals while actively participating. This was allowed and some drafts were sometimes part of the lectures during the sessions. Their drafts were used as practical samples of good or bad qualitative proposal drafting.

\section{Bibliography}

1. Sandelowski M and Barroso J. "Reading qualitative studies". International Journal of Qualitative Methods 1.1 (2002): 74-108.

2. Sandelowski M and Leeman J. "Writing usable qualitative health research findings". Quality Health Research 22.10 (2012): 1404-1413.

3. Chenail RJ. "A compendium of teaching and learning qualitative research resources". Tqr Community Qualitative Research Resource (2012).

4. Clark AM and Sousa BJ. "New possibilities and chapters: Qualitative research and the international journal of qualitative methods". International Journal of Qualitative Methods 14.4 (2015): 1609406915614130.

5. Savenye WC and Robinson RS. "Using qualitative research methods in higher education". Journal of Computing in Higher Education 16.2 (2005): 65-95.
6. Collins CS and Cooper JE. "Emotional intelligence and the qualitative researcher". International Journal of Qualitative Methods 13.1 (2014): 88-103.

7. Spiers JA., et al. "Strategies for engaging undergraduate nursing students in reading and using qualitative research". (2012).

8. Lave J and Wenger E. "Situated learning: Legitimate peripheral participation". Cambridge university press (1991).

9. Schulze S. "Mentoring novice researchers in higher education: A" communities of practice" perspective". Koers: Bulletin for Christian Scholarship= Koers: Bulletin vir Christelike Wetenskap 74 (2009): 117-137.

10. Kock N., et al. "Furthering information systems action research: A post-positivist synthesis of four dialectics". Journal of AIS 9 (2008).

11. Clark AM and Thompson DR. "Five tips for writing qualitative research in high-impact journals: Moving from \#bmjnoqual". International Journal of Qualitative Methods 15.1 (2016): 1609406916641250.

12. Colaizzi PF. "Psychological research as the phenomenologist views it". In: Valle RS, King M, editors. Existential-phenomenological alternatives for psychology: Oxford University Press (1978): 6.

13. Speziale HS., et al. "Qualitative research in nursing: Advancing the humanistic imperative". Lippincott Williams and Wilkins (2011).

14. Luttrell W. "Qualitative educational research: Readings in reflexive methodology and transformative practice". New York; London: Routledge (2010).

15. Glesne C. "Becoming qualitative researchers: An introduction". $4^{\text {th }}$ ed. Boston: Pearson (2011).

\section{Assets from publication with us}

- Prompt Acknowledgement after receiving the article

- Thorough Double blinded peer review

- Rapid Publication

- Issue of Publication Certificate

- High visibility of your Published work

Website: www.actascientific.com/

Submit Article: www.actascientific.com/submission.php Email us: editor@actascientific.com

Contact us: +919182824667 